\title{
VALORES MOTIVACIONAIS NAS ORGANIZAÇÕES: UM ESTUDO COM DIFERENTES GRUPOS DE TRABALHO DE SERVIDORES PÚBLICOS DA EDUCAÇ̃̃O
}

\author{
iD Paulo Roberto Borghi Moreira ${ }^{1}$ (D) Aridelmo Teixeira $^{2}$ (D) ${ }$ Octavio Locatelli ${ }^{3}$ \\ ${ }^{1}$ Fucape Business School. Vitória, ES - Brasil.paulo.moreira@ifes.edu.br \\ ${ }^{2}$ Fucape Business School. Vitória, ES-Brasil. aridelmo@fucape.br \\ ${ }^{3}$ Fucape Business School.Vitória, ES - Brasil. octaviolocatelli@ hotmail.com
}

\section{Resumo}

Objetivo: Esta pesquisa teve como objetivo identificar os Valores Motivacionais que se destacam na percepção dos colaboradores de uma Instituição Pública de Ensino.

Metodologia: O instrumento aplicado foi o questionário eletrônico sobre as características demográficas e o modelo da estrutura de valores básicos utilizando a escala de Schwartz (1992), Portrait Value Questionnaire (PVQ). A coleta de dados foi realizada em todos os campi do Instituto Federal do Espírito Santo (IFES), com amostra de 549 servidores, os quais foram analisados por estatística descritiva e regressão múltipla.

Principais Resultados: Os resultados sugerem que há percepções distintas sobre os valores motivacionais percebidos na instituição. Quanto ao grupo de trabalho Docentes, pode-se considerar que dão mais importância à transmissão dos conhecimentos para gerações futuras, priorizando o cuidado com a preservação do planeta e das relações. Quanto ao grupo Técnicos Administrativos pode-se destacar que apreciam a segurança nas relações e a continuidade dos processos.

Palavras-chave: Valores motivacionais. Grupos de trabalho. Servidores da educação pública.

\section{MOTIVATIONAL VALUES IN ORGANIZATIONS: A STUDY WITH DIFFERENT WORKING GROUPS OF PUBLIC EDUCATION SERVANTS}

\begin{abstract}
Objective: This research aimed to identify the Motivational Values that stand out in the perception of employees of a Public Educational Institution

Methodology: The instrument applied was the electronic questionnaire on demographic characteristics and the basic value structure model using the Schwartz (1992), Portrait Value Questionnaire (PVQ) scale. Data collection was carried out at all campuses and rectory of the Federal Institute of Espírito Santo (IFES), whose sample was composed by 549 servers, and analyzed through descriptive statistics and multiple regression.

Main results: The results suggest that there are different perceptions about the motivational values perceived in the institution. As for the
\end{abstract}

working group of Professors, it can be considered that they give more importance to transmit knowledge to future generations, prioritizing care with the preservation of the planet and relationships. As for the Administrative Technicians group, it can be highlighted that they appreciate the security of relationships and the continuity of processes.

Keywords: Motivational values. Work groups. Public education servers.

\section{VALORES MOTIVACIONALES EN LAS ORGANIZACIONES: UN ESTUDIO CON DIFERENTES GRUPOS DE TRABAJO DE SERVIDORES PÚBLICOS DE LA EDUCACIÓN}

\begin{abstract}
Resumen
Objetivo: Esta investigación tuvo como objetivo identificar los Valores Motivacionales que se destacan en la percepción de los empleados de una Institución Educativa Pública.

Metodología: El instrumento aplicado fue uma encuesta electrónica sobre las características demográficas y el modelo de la estructura de valores básicos utilizando la escala de Schwartz (1992), Portrait Value Questionnaire (PVQ). La recolección de datos fue realizada en todos los campi del Instituto Federal de Espírito Santo (IFES), con una muestra de 549 servidores, analizados por estadística descriptiva y regresión múltiple.

Principales resultados: Los resultados sugieren que existen diferentes percepciones sobre los valores motivacionales percibidos en la institución. En cuanto al grupo de trabajo de Profesores, se puede considerar que dan más importancia a la transmisión del conocimiento a las generaciones futuras, priorizando el cuidado con la preservación del planeta y las relaciones. En cuanto al grupo de Técnicos Administrativos, se puede destacar que aprecian la seguridad de las relaciones y la continuidad de los procesos.
\end{abstract}

Palabras-clave: Valores de motivación. Grupos de Trabajo. Servidores de Educación Pública.

\section{Cite as / Como citar}

American Psychological Association (APA)

Moreira, P. R. B., Teixeira, A., \& Locatelli, O. (2020, July/Sept.). Valores motivacionais nas organizações: um estudo com diferentes grupos de trabalho de servidores públicos da educação. Iberoamerican Journal of Strategic Management (IJSM), 19(3), 116-145.

https://doi.org/10.5585/riae.v19i3.14745.

MOREIRA, P. R. B.; TEIXEIRA, A.; LOCATELLI, O. Valores motivacionais nas organizações: um estudo com diferentes grupos de trabalho de servidores públicos da educação Iberoamerican Journal of Strategic Management (IJSM), v. 19, n. 3, p. 116-145, July/Sept. 2020.

https://doi.org/10.5585/riae.v19i3.14745. 


\section{Introdução}

A motivação humana é uma característica de organizar as distintas necessidades, objetivos e motivos (Schwartz \& Bardi, 2001). Nas organizações a motivação é o mecanismo responsável pela intensidade, direção e persistência, do empenho de um indivíduo ou um grupo de pessoas para o alcance de determinada meta (Robbins, Judge, \& Sobral, 2011).

Além disso, percebemos que as organizações estão vivenciando uma experiência inédita, pois as alterações drásticas nas áreas econômicas, tecnológicas e de mercado têm exigido dos gestores a revisão de diversos conceitos e paradigmas, principalmente no que diz respeito ao capital humano, confirmando a inevitável necessidade de valorização e motivação dos funcionários (Marras, 2011).

As pessoas diferem substancialmente em demonstrar suas motivações nas organizações. Tanto é verdade que uma tarefa que determinada pessoa se sente altamente motivada a realizar, para outra pode não fazer sentido, e isso ocorre porque os indivíduos ou grupos possuem valores diferentes, necessidades distintas, bem como formação de vida e profissional diferenciada (Ferreira, Fuerth, \& Esteves, 2006).

Nesse âmbito, pesquisas de diversos autores têm contribuído para o estudo dos valores pessoais que vêm colaborando na explicação da motivação, como Parsons, Kluckhohn e Rokeach (Ros, 2006), inclusive alguns brasileiros, a exemplo de Gouveia (2003) e Tamayo e Porto (2005). Dentre esses estudos, o do autor psicólogo israelense Shalom Schwartz $(1992,2005)$ destacou-se e vem inspirando pesquisadores de áreas como a Administração.

Schwartz foi criterioso ao montar um grupo internacional de pesquisa para estudar os tipos motivacionais de valores em diversas culturas, resultando em um modelo de estrutura de valores universais e dinâmicos, testado empiricamente em mais de 60 países, sendo que, aqui no Brasil, o pesquisador responsável por testar o modelo de Schwartz foi Álvaro Tamayo (Tamayo \& Paschoal, 2003; Calvosa, Serra, \& Almeida, 2011).

Os tipos motivacionais de valores, representados neste trabalho como valores motivacionais, são as metas individuais, norteadoras dos comportamentos e das avaliações de cada pessoa, isto é, são as metas motivacionais as quais focam os alvos que as pessoas pretendem alcançar na vida (Schwartz, 2005), desta forma, não estão delimitados a específicas situações, porém se organizam conforme o seu grau de importância. Para Tamayo e Porto (2005, p. 8), os valores orientam e guiam a vida das pessoas.

Para Tamayo e Pascoal (2003, p. 41), [...] as pesquisas foram postuladas em diversas motivações, submetidas à verificação empírica. As diversas motivações foram identificadas por meio das prioridades dadas pelas pessoas aos valores. Schwartz (1992) argumenta que existem dez motivações e suas metas: as cinco primeiras de relação pessoal (poder, realização, hedonismo, estimulação e autodeterminação); três relacionadas à família, à organização e à sociedade (tradição, conformidade e benevolência); e as duas últimas referem-se tanto à própria pessoa, quanto aos outros (universalismo e segurança). 
Estudos como o de Lombardi, Araujo e Teixeira (2010) têm utilizado o conjunto de valores e tipos motivacionais de Schwartz para tentar identificar a hierarquia dos valores básicos em estudantes de instituições universitárias.

Como os valores motivacionais são uma estrutura já consolidada de forma universal, concebendo um modelo dinâmico com tipos motivacionais, tal dinâmica permite que ela seja aplicada em diversas culturas e em distintos grupos sociais podendo apresentar diferentes pesos em alguns tipos motivacionais, dependendo do grupo em que esse instrumento for aplicado para estudo (Tamayo, 2007).

Segundo Saraiva (2002), o ambiente das instituições públicas conta com uma administração burocrática, e nas quais muitas situações engessam os processos devido à rigidez das normas e dificuldade de se adotar qualquer alternativa de reformulação. Dessa forma, servidores públicos de carreiras distintas, mesmo com todos os requisitos necessários, não têm a possibilidade direta de migração para outra carreira - só por meio de um novo concurso público conforme expressa a Lei n. ${ }^{\circ}$ $8.112(1990)$.

Observou-se, assim, que esta pesquisa pode colaborar de forma empírica a identificar quais Valores Motivacionais distinguem diferentes grupos de trabalho das instituições públicas de ensino. Dessa forma, o objetivo deste trabalho é identificar os Valores Motivacionais que se destacam no grupo de trabalho Docentes e no grupo de trabalho Técnicos Administrativos presentes em uma Instituição Pública de Ensino e sua relação com a motivação em cada grupo.

Esses dois grupos não são homogêneos porque desempenham atividades distintas, e o presente estudo colabora empiricamente ao demonstrar que hipóteses utilizando o mesmo valor de ordem superior, para ambos os grupos, recebem diferentes pesos para cada grupo.

Este artigo contribui porque há necessidade de aumentar o estudo acerca dos Valores Pessoais e tem como foco a análise de diferentes grupos de trabalhos das instituições públicas de ensino. Além disso, visa apresentar um panorama da situação que aborda a motivação dos servidores do IFES para que os gestores possam adotar estratégias e desenvolver políticas de gestão de pessoas e capacitação mais específicas para esses dois grupos, além do perfil motivacional, que visem à manutenção da motivação em seu quadro de pessoal (Brown et al., 2003; Carrara, Nunes, \& Sarsur, 2014). Isso permite elaborar mecanismos que possam dinamizar o desempenho, bem como reter o capital humano qualificado, que vem se tornando escasso nas organizações (Mitchell et al., 2001; Holtom et al., 2008; Dutra, 2011; Pogorzelski, Harriott, \& Hardy, 2011).

\section{Fundamentação teórica}

\subsection{Valores motivacionais}

O que pode diferenciar um valor dos outros é o tipo de motivação que cada um expressa (Tamayo, 2007). 
Schwartz (1992, 2005) conseguiu extrair de seus achados nas pesquisas transculturais um modelo dinâmico e universal que pode ser utilizado em várias culturas e em diversos países. Os dez tipos motivacionais encontrados na pesquisa formaram uma estrutura circular e podem apresentar várias polaridades (Tamayo, 1994).

Conforme informa Schwartz (2005), quanto mais próximos dois tipos motivacionais estiverem em qualquer uma das direções em torno do círculo, representado na Figura 1, mais semelhantes serão suas motivações subjacentes. Como exemplo, tradição e conformidade estão localizadas em um mesmo campo porque elas se associam ao mesmo valor de ordem superior, que é Conservação. Conformidade está mais para o centro, enquanto tradição, mais para a periferia, significando que valores de tradição conflitam fortemente com valores opostos.

Figura 1 - Estrutura circular dos valores ilustrando conflito e congruência entre os tipos motivacionais

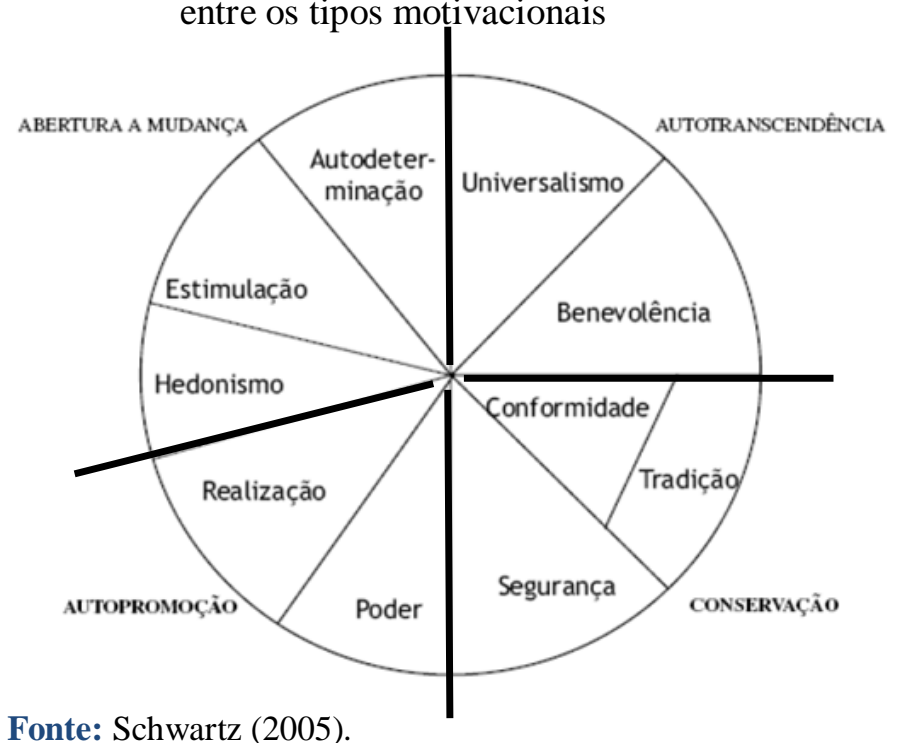

Fonte: Schwartz (2005).

Podemos constatar no modelo apresentado na Figura 1 duas dimensões bipolares observadas nos valores pessoais (Abertura à Mudança versus Conservação e Autotranscendência versus Autopromoção), conforme citam Tamayo e Porto (2009).

Schwartz $(1999,2012)$ explica que a teoria se refere aos valores básicos que as pessoas reconhecem em várias culturas. Identificam-se dez tipos motivacionais distintos de valores e especificam as relações dinâmicas entre eles. Alguns valores interagem de forma conflitante uns com os outros, a exemplo de hedonismo e conformidade, enquanto outros são compatíveis, tais como realização e poder. A estrutura circular de valores, disposta na Figura 1, refere-se a essas relações de conflito e de congruência entre os valores. 
Quadro 1 - Valores de Ordem Superior, Tipos Motivacionais e Metas

\begin{tabular}{|c|c|c|}
\hline $\begin{array}{c}\text { Conjuntos de } \\
\text { valores }\end{array}$ & Metas motivacionais & $\begin{array}{c}\text { Serve a } \\
\text { interesses }\end{array}$ \\
\hline $\begin{array}{l}\text { Abertura à } \\
\text { Mudança }\end{array}$ & Composto por: Autodeterminação, Estimulação e Hedonismo & \\
\hline Autodeterminação & Independência de pensamento e ação; criar e explorar & Individuais \\
\hline Estimulação & $\begin{array}{l}\text { Manter-se em excelente nível de ativação; excitação, novidade e } \\
\text { desafio na vida }\end{array}$ & Individuais \\
\hline Hedonismo & $\begin{array}{l}\text { Prazer, procura satisfazer seus desejos; curte os prazeres da vida, } \\
\text { quer gozar a vida }\end{array}$ & Individuais \\
\hline Autopromoção & Composto por: Realização e Poder & \\
\hline Realização & Realizar padrões internos de excelência & Individuais \\
\hline Poder & Status social e prestígio & Individuais \\
\hline Conservação & Composto por: Segurança, Tradição e Conformidade & \\
\hline Segurança & Estabilidade da sociedade, das relações e da própria pessoa & Mistos \\
\hline Tradição & $\begin{array}{l}\text { Respeito, compromisso e aceitação dos costumes e ideias que uma } \\
\text { cultura impõe ao indivíduo }\end{array}$ & Coletivos \\
\hline Conformidade & Restringir ações, inclinações e impulsos socialmente indesejáveis & Coletivos \\
\hline Autotranscendência & Composto por: Benevolência e Universalismo & \\
\hline Benevolência & Preservação e bem-estar das pessoas mais próximas & Coletivos \\
\hline Universalismo & $\begin{array}{l}\text { Entender, apreciar, tolerar e proteger tendo em vista o bem-estar } \\
\text { da humanidade e a natureza }\end{array}$ & Mistos \\
\hline
\end{tabular}

Fonte: Adaptado de Schwartz (1992) e Sambiase-Lombardi et al. (2010, p. 4).

Pode-se observar no Quadro 1 que na primeira coluna estão os 4 (quatro) valores de ordem superior (Abertura à Mudança; Autopromoção; Conservação; Autotranscendência), e logo abaixo deles encontram-se os seus respectivos tipos motivacionais. Na segunda coluna são descritas as metas motivacionais, e na terceira traz a qual interesse cada valor serve (individual, coletivo ou misto) (Schwartz, 1992).

Schwartz $(1999,2012)$ explica que a teoria se refere aos valores básicos que as pessoas reconhecem em várias culturas. Identificam-se dez tipos motivacionais distintos de valores e especificam as relações dinâmicas entre eles. Alguns valores interagem de forma conflitante uns com os outros, a exemplo de hedonismo e conformidade, enquanto outros são compatíveis, tais como realização e poder. A estrutura circular de valores, disposta na Figura 1, refere-se a essas relações de conflito e de congruência entre os valores.

Para Schwartz (1992, 2006), ao pensar em nossos valores, refletimos o que é importante para nós em nossa vida. Cada pessoa possui vários valores (realização, segurança, benevolência) com diferentes graus de importância. Um valor particular pode ser muito importante para uma pessoa, mas sem importância para o outro.

A teoria aprofunda-se mais quando aborda a estrutura das relações de valores (Schwartz, 1992; Smith \& Schwartz, 1997), por exemplo, se procuramos alcançar valores de realização normalmente entramos em conflito com o valor benevolência. Ao buscar o sucesso para si mesmo, o indivíduo tende a obstruir as ações destinadas a reforçar o bem-estar de outras pessoas que precisam de sua ajuda, esclarecem Davidov, Schmidt e Schwartz (2008).

No entanto, ao ir atrás dos valores realização e poder, geralmente estes são compatíveis. Ao buscar o sucesso pessoal para si mesmo, o indivíduo tende a fortalecer e ser reforçado por ações 
destinadas a fortalecer a própria posição social e autoridade sobre os outros. Outro exemplo: ao procurar a novidade e a mudança (os valores de estimulação), ele é suscetível de prejudicar a preservação de costumes veneráveis (valores de tradição). Em contraste, perseguir valores de tradição é similar se buscarmos os valores de conformidade. Ambos motivam ações de submissão às expectativas externas, conforme explicam Bilsky, Janik e Schwartz (2011).

Na teoria de Schwartz, o valor Autotranscendência e o valor Autopromoção possuem uma relação dicotômica, e quando um desses valores tende a apresentar resultados altos (mais importante), o outro apresenta-se com valores baixos (menos importante). O mesmo acontece com relação aos valores Conservação e Abertura à Mudança, o que reforça a condição de oposição entre os polos da estrutura circular (Schwartz \& Boehnke, 2004).

Para Houston (2000), as pessoas ocupadas no setor público têm valores e motivos diferentes dos daquelas empregadas em organizações privadas. Além disso, num contexto dinâmico e com muitas incertezas, os valores e motivações são de grande relevância para a decisão da carreira a seguir e também na condução ao longo da vida (Abessolo, Rossier, \& Hirschi, 2017).

\subsection{Os institutos federais de educação profissional, científica e tecnológica}

No início do século XXI, o Brasil passa por diversas mudanças, e na área da educação federal, o país assume um posicionamento progressista, deixando para trás a estagnação vivenciada no século anterior. Dessa forma, o governo federal passa a responder às demandas educacionais com uma postura democrático-popular (Brasil, 2016).

De acordo com Tavares (2012), neste período o governo fez uma reformulação significativa na Rede Federal de Educação e ampliou a oferta de ensino por intermédio da Lei 11.892 (2008) com a criação da Rede Federal de Educação Profissional, Científica e Tecnológica, e simultaneamente, com a implantação dos Institutos Federais de Educação, Ciência e Tecnologia (IFs) em todo o território nacional. Em sua fase inicial, a implantação deu-se por meio da união das Escolas Técnicas Federais, das Escolas Agrotécnicas e algumas Escolas Técnicas vinculadas às Universidades, formando assim uma única autarquia.

Ela é constituída por 38 institutos, com diversos campi distribuídos por todo Brasil, opera do ensino médio integrado ao técnico (50\% das vagas), licenciaturas (20\%) e cursos superiores de tecnologia ou bacharelados tecnológicos (30\%), e consegue ofertar ainda especializações, mestrados e doutorados profissionais (Pacheco, 2011). Na pesquisa de Oliveira et al. (2015), apontou-se que nos últimos anos o crescimento dos Institutos Federais apresentou um aumento expressivo, e isso possibilitou maior acesso à educação de qualidade a muitos brasileiros, passando de 154 campi em 2005 para 562 no ano de 2014. 
O que torna os IFs distintos das Universidades é que além de continuar ofertando vagas ao ensino médio, os Institutos podem oferecer cursos superiores e de pós-graduação em áreas estratégicas conforme a demanda econômica da região (Tavares, 2012).

Para prestar os serviços públicos de educação nos IFs, essa autarquia vinculada ao Ministério da Educação (MEC) conta em seu quadro de servidores com dois grupos principais: a) o Docente do Magistério do Ensino Básico, Técnico e Tecnológico; b) o TécnicoAdministrativo em Educação (Pacheco, 2011).

\subsection{O Instituto Federal do Espírito Santo (IFES)}

Na realização do presente estudo, foi utilizado o IFES (instituição federal de educação localizada no estado do Espírito Santo) como local para coleta de dados dos servidores. Desta forma, uma breve descrição dessa entidade é apresentada com o objetivo de ilustrar o contexto onde a pesquisa foi executada. Detalhes da parte empírica estão na seção de metodologia desta pesquisa.

Os Cefetes e as Escolas Agrotécnicas dos municípios de Alegre, de Colatina e de Santa Teresa passaram a ser campi do IFES. Com o processo de expansão, o instituto conta com 21 campi: Campus Alegre, Aracruz, Barra de São Francisco, Cachoeiro de Itapemirim, Cariacica, Centro Serrano, Colatina, Guarapari, Ibatiba, Itapina, Linhares, Montanha, Nova Venécia, Piúma, São Mateus, Serra, Santa Teresa, Venda Nova, Viana, Vila Velha e Vitória (Relatório de Gestão, 2015).

Atendem a um público bem diversificado e possuem na maioria dos campi a oferta de cursos com diferentes níveis; além dos técnicos, concomitantes ou integrados, oferecem também graduações e pós-graduações, como especialização e mestrados, bem como cursos do módulo de Educação a Distância (EaD) (Relatório de Gestão, 2015).

\subsection{Diferentes grupos de trabalho de servidores da educação}

Todos os campi são estruturados em duas áreas: área administrativa (responsável pela gestão das atividades focadas na administração) e área acadêmico-pedagógica (responsável pelas ações direcionadas ao ensino, pesquisa e extensão) (Relatório de Gestão, 2015, p.81).

Docentes: Os Institutos têm sua base no ensino verticalizado, em que os docentes exercem suas atividades em vários níveis com os alunos, compartilhando os espaços pedagógicos e laboratórios, além de tentar estabelecer momentos formativos do curso técnico ao doutorado (Pacheco, 2011).

A carreira do Docente do Magistério do Ensino Básico Federal, segundo a Lei no 12.772, de 28 de dezembro de 2012, é composta das seguintes classes: DI; DII; DIII; DIV e Titular. No $§ 5^{\circ}$ desta Lei informa-se que o regime jurídico dos cargos do Plano de Carreiras e Cargos de Magistério Federal é o instituído pela Lei n. ${ }^{\circ}$ 8.112, de 11 de dezembro de 1990, observadas as disposições desta Lei. 
Técnicos Administrativos: A carreira do Técnico-Administrativo em Educação, segundo a Lei $\mathrm{n}^{\mathrm{o}}$ 11.091, de 12 de janeiro de 2005, é composta por 5 (cinco) níveis de classificação, com 4 (quatro) níveis de capacitação cada.

No art. $7^{\circ}$, os cargos do Plano de Carreira são organizados em 5 (cinco) níveis de classificação, A, B, C, D e E de acordo com o disposto no inciso II do art. $5^{\circ}$ e no Anexo II desta Lei (nível de classificação é o conjunto de cargos de mesma hierarquia, classificados a partir do requisito de escolaridade, nível de responsabilidade, conhecimentos, habilidades específicas, formação especializada, experiência, risco e esforço físico para o desempenho de suas atribuições).

\subsection{Hipóteses}

A universalidade dos valores humanos é explicada por Schwartz (1994) em razão da ideia de eles expressarem requisitos básicos à existência humana. $\mathrm{O}$ autor defendeu que valores são crenças as quais transcendem situações e ações específicas, que orientam a escolha e o julgamento das ações, os indivíduos e os fatos e que são ordenados de acordo com a importância relativa recebida ante aos outros valores. A importância de um valor para uma pessoa em relação aos demais valores é o critério o qual faz com que determinadas ações sejam ativadas. Valores são antecedentes de ações, promotoras de metas ou intentos correspondentes.

Levando em consideração que as 4 (quatro) dimensões ou valores de ordem superior (Abertura à Mudança versus Conservação e Autotranscendência versus Autopromoção) estão dispostos em polos contrários, as hipóteses são elaboradas levando em consideração essa característica da estrutura circular dos valores de Schwartz.

Para análise de comparação em cada grupo, serão propostas duas hipóteses relacionadas ao mesmo valor de ordem superior, uma para os Docentes e uma para os Técnicos Administrativos.

Para Schwartz (1992), as pessoas conservadoras tendem a priorizar um dos valores pessoais, que é a segurança, tendo como meta motivacional a estabilidade coletiva e individual. Como estamos pesquisando grupos de servidores públicos federais, a estabilidade converge com o que esclarece o art. 41 da Constituição Federal (1998), o qual descreve serem estáveis, após três anos de efetivo exercício, os servidores nomeados em virtude de concurso público. Nos termos do $\S 1^{\circ}$, o servidor público estável só perderá o cargo em razão de sentença judicial transitada em julgado ou mediante processo administrativo no qual lhe seja assegurada ampla defesa. Ou seja, pessoas inseridas no serviço público visam com destaque à estabilidade.

Diante do apresentado, propuseram-se as duas primeiras hipóteses:

H1: Há uma relação positiva entre o valor pessoal de Conservação e a motivação do grupo de trabalho de Docentes.

H2: Há uma relação positiva entre o valor pessoal de Conservação e a motivação do grupo de trabalho de Técnicos Administrativos. 
Dada a relação de oposição conceitual e a associação negativa, encontrada na teoria de valores de Schwartz (1994), entre os polos de Autotranscendência e Autopromoção, supôs-se que fatores relacionados positivamente a um polo do modelo teórico de valores de Schwartz apresentariam relação negativa com o polo diametralmente oposto.

O valor de Abertura à Mudança é antagônico ao valor citado nas hipóteses anteriores, e a dimensão de Abertura à Mudança enfatiza a independência de pensamento (Schwartz \& Ros, 1995; Schwartz \& Bardi, 1997), ação e sentimentos e prontidão para a mudança (tipos motivacionais: autodeterminação e estimulação), (Sagiv \& Schwartz, 2000; Schwartz et al., 2012). Desta forma, em oposição, sugeriu-se que:

H3: Há uma relação negativa entre o valor pessoal de Abertura à Mudança e a motivação do grupo de trabalho de Docentes.

H4: Há uma relação negativa entre o valor pessoal de Abertura à Mudança e a motivação do grupo de trabalho de Técnicos Administrativos.

O valor de Autotranscendência capta a preocupação voluntária com o bem-estar e os interesses dos outros, como ser útil, honesto, responsável, leal, criar amizades verdadeiras e o perdão (Schwartz et al., 2001). Também destaca a necessidade de sobrevivência de indivíduos e grupos, prezando pela justiça social, igualdade, paz, proteção do meio ambiente e do mundo (tipos motivacionais: universalismo e benevolência) (Schwartz, Verkasalo, Antonovsky, \& Sagiv, 1997). E tendo em vista que os grupos pesquisados fazem parte de uma instituição pública de ensino voltada ao fomento tecnológico e preparação dos alunos, propôs-se que:

H5: Há uma relação positiva entre o valor pessoal de Autotranscendência e a motivação do grupo de trabalho de Docentes.

H6: Há uma relação positiva entre o valor pessoal de Autotranscendência e a motivação do grupo de trabalho de Técnicos Administrativos.

O polo Autopromoção agrega os tipos motivacionais poder e realização e expressa a motivação do indivíduo em promover seus próprios interesses (Schwartz, 2005). Para Tamayo e Paschoal (2003), esta dimensão motivacional dá ênfase para as pessoas que estão apreensivas com os seus próprios resultados, sem preocupação com os resultados coletivos, numa luta para ser melhor que os outros, para ter prestígio, influência e poder. E levando em consideração que os grupos fazem parte de uma instituição de ensino, onde os resultados dos alunos têm grande relevância, sugeriu-se que:

H7: Há uma relação negativa entre o valor pessoal de Autopromoção e a motivação do grupo de trabalho de Docentes.

H8: Há uma relação negativa entre o valor pessoal de Autopromoção e a motivação do grupo de trabalho de Técnicos Administrativos.

\section{Metodologia}


Esta pesquisa é descritiva, com abordagem quantitativa, utiliza aplicação de questionário adaptado para a coleta de dados, estratificação amostral, adota também estatística descritiva e regressão múltipla. É de corte transversal, com a coleta de dados (Hair, Black, Babin, Anderson, \& Tatham, 2005).

Optou-se pela regressão múltipla por ser um método de análise quando o problema de pesquisa envolve uma única variável dependente relacionada a um conjunto de variáveis independentes. Seu objetivo é prever as mudanças na variável dependente como resposta às mudanças nas variáveis independentes, por meio da regra estatística dos mínimos quadrados ordinários (MQO) por ser um modelo que relaciona as variáveis que tenham um menor erro possível (Hair, Babin, Money, \& Phillip, 2009, p. 144).

Os modelos utilizados na regressão múltipla encontram-se apresentados abaixo:

Modelos (1) e (2) usando a base de dados completa:

$$
\begin{aligned}
& \text { motivacao } \text { Docente }=\beta_{0}+\beta_{1} A T+\beta_{2} A M+\beta_{3} C O+\beta_{4} A P+\mu \\
& \text { motivacao } \text { Tecaion }=\beta_{0}+\beta_{1} A T+\beta_{2} A M+\beta_{3} C O+\beta_{4} A P+\mu
\end{aligned}
$$

Nota:

motivacao : Motivação (variável dependente);

$\beta_{0}:$ Constante/Interseção;

$\beta_{1} A T$ : Autotranscendêncial(variável independente);

$\beta_{2} A M$ : Abertura à Mudança (variável independente);

$\beta_{3} \mathrm{CO}$ : Conservação (variável independente);

$\beta_{4} A P$ : Autopromoção (variável independente);

$\mu:$ Erro.

Os campi foram escolhidos por conveniência, totalizando 21 campi, além da reitoria, localizada na capital do ES (Campus Alegre, Aracruz, Barra de São Francisco, Cachoeiro de Itapemirim, Cariacica, Centro Serrano, Colatina, Guarapari, Ibatiba, Itapina, Linhares, Montanha, Nova Venécia, Piúma, São Mateus, Serra, Santa Teresa, Venda Nova, Viana, Vila Velha e Vitória). Eles responderam por completo ao questionário, num total de aproximadamente 540 servidores, dos quais dois grupos foram estudados (Docentes + Técnicos Administrativos), de uma amostra de 25,12\% dos respondentes referente à população do IFES no intuito de aproximar ao máximo a característica da população estudada.

A coleta de dados foi composta pelo Termo de Consentimento Livre e Esclarecido - TCLE, solicitado pelo Conselho de Ética da instituição, tendo em vista que tal pesquisa foi realizada com pessoas, em conjunto com o questionário eletrônico (ferramenta google docs) sobre características demográficas e o modelo do instrumento de valores básicos com utilização da escala de Schwartz 
(1992), Portrait Value Questionnaire (PVQ) ou Questionário de Perfis de Valores (QPV), validado no Brasil por Tamayo e Porto (2009).

A pesquisa consistiu em responder a 50 itens por completo do questionário - com questões predominantemente fechadas, caso contrário a participação do respondente já era invalidada automaticamente pela ferramenta. A estimativa para conclusão das respostas era de 5 minutos. $\mathrm{O}$ questionário foi enviado eletronicamente a uma população total do IFES de 2.150 servidores.

O instrumento de Schwartz, com 40 afirmações, possui as seguintes características: o quanto o respondente se parecia com cada questão apresentada, como exemplo para representar o valor Criatividade é "Pensar em novas ideias e ser criativa é importante para ela. Ela gosta de fazer coisas de maneira própria e original". Após o entendimento a pessoa atribuiria em uma escala de 1 a 5 , em que 1 = "Se parece muito comigo" e 5 "Não se parece nada comigo" (Schwartz, 2005; Tamayo \& Porto, 2009, p. 373).

As respostas indicam os tipos motivacionais de cada participante e consequentemente seus valores pessoais (Tamayo \& Porto, 2009).

Já a variável dependente: "Nível de Motivação em trabalhar na atual Instituição Pública de Educação (IFES)" também foi mensurada por uma escala Likert de 5 pontos, onde 1 refere-se a "muito motivado" e 5 a "nada motivado", composta por uma questão.

O questionário foi respondido por servidores de todos os campi, reduzindo dessa forma vieses relacionados à localidade. Assim, 30\% dos participantes responderam em novembro de 2015, 38\% responderam à pesquisa em dezembro de 2015, e 32\% no período de janeiro e fevereiro de 2016.

Conforme pôde-se observar no modelo apresentado, esta pesquisa possui uma variável dependente: Nível de Motivação em trabalhar na atual Instituição Pública de Educação (IFES); e quatro variáveis independentes: Conservação (CO), Abertura à Mudança (AM), Autotranscendência (AT), e Autopromoção (AP), as quais se referem aos conjuntos de valores da teoria de Schwartz (1992). Este estudo se propôs a analisar 2 (dois) grupos distintos, e tal modelo foi aplicado em cada grupo de trabalho de servidores da educação.

Após a coleta, os dados foram submetidos às análises estatísticas, realizadas com o software SPSS, versão 22.

\section{Análise dos dados}

\subsection{Estatística descritiva}

A amostra teve 549 respondentes, em sua maioria de Técnicos Administrativos - 327 respondentes - o que equivale a $60,8 \%$; e do grupo Docentes teve 222 participantes, equivalendo a $39,2 \%$. Levando em consideração que o PVQ é composto por 40 itens, o tamanho da amostra foi aceitável porque, conforme cita Hair, Black, Babin, Anderson, Tatham (2005, p. 148), deve haver no mínimo cinco observações para cada item ou variável independente. Dessa forma, como estamos 
analisando grupos distintos, mesmo com a divisão da amostra por cada grupo, ainda assim o tamanho dela atende ao esperado.

De forma geral, mesclando os dois grupos dentre os 21 campi, os três que tiveram maiores representações foram, campus Vitória (19,1\%); campus Guarapari (8\%) e campus Itapina $(7,4 \%)$. Referente ao tempo de trabalho no Ifes, ficaram bem próximas as alternativas de 1 a 3 anos $(25,8 \%)$ e 4 a 6 anos $(24,9 \%)$, e isso leva a crer com esses dados que a instituição teve um aumento significativo de servidores nos últimos anos com a expansão da instituição.

Referente ao gênero está muito próximo de $50 \%$ para cada um, masculino $(49,3 \%)$ e feminino (50,7\%). A faixa etária dos participantes se concentra principalmente entre 31 e 40 anos $(36,9 \%)$ e de 41 a 50 anos $(24,4 \%)$. O estado civil predominante é Casado (a) (59,5\%). Já o nível de escolaridade mais recorrente é a Especialização (41,8\%), seguido de Mestrado (28,9\%) e Doutorado (15,3\%).

Tabela 1 - Estatística descritiva

\begin{tabular}{ll|c|c|c}
\hline Tipo de servidor & & N & Média & Desvio padrão \\
\hline Docente & MOTIVAÇÃO & 222 & 1,937 & 0,656 \\
& AM & 222 & 2,104 & 0,534 \\
& AP & 222 & 2,893 & 0,683 \\
& CO & 222 & $\mathbf{2 , 2 7 5}$ & $\mathbf{0 , 4 3 1}$ \\
& AT & 222 & 1,679 & 0,450 \\
\hline Técnico Administrativo & MOTIVAÇÃO & 327 & 2,547 & 0,989 \\
& AM & 327 & 2,322 & 0,483 \\
& AP & 327 & $\mathbf{3 , 0 7 2}$ & $\mathbf{0 , 4 3 7}$ \\
& CO & 327 & 2,460 & 0,480 \\
& AT & 327 & 1,788 & 0,409 \\
\hline
\end{tabular}

Fonte: Dados da pesquisa.

A Tabela 1 apresenta a estatística descritiva dos grupos estudados, e neste momento percebemos que o valor Conservação teve mais importância para os Docentes, com média 2,27 e o menor desvio padrão $(0,43)$. Referente aos Técnicos Administrativos, o valor de maior influência é Autopromoção, com média 3,07 e desvio padrão 0,44 , sugerindo que há diferença na percepção dos valores entre os grupos.

\subsection{Regressão múltipla}

O resumo do modelo e a análise de variância são apresentados como significativo das variáveis independentes em relação à variável dependente, conforme demonstrado na Tabela 2. 
Tabela 2 - Resumo do modelo

\begin{tabular}{l|c|c|r|r|rr|r}
\hline \multicolumn{1}{c|}{ Tipo servidor } & Modelo & $\mathbf{R}$ & $\begin{array}{c}\mathbf{R} \\
\text { quadrado }\end{array}$ & $\begin{array}{c}\text { R } \\
\text { quadrado } \\
\text { ajustado }\end{array}$ & $\begin{array}{c}\text { Erro padrão da } \\
\text { estimativa }\end{array}$ & Durbin-Watson \\
\hline Docente & 1 &, $376^{\mathrm{a}}$ &, 141 &, 125 &, 6136 & 2,048 \\
Técnico Administrativo & 2 &, $440^{\mathrm{a}}$ &, 194 &, 184 &, 8921 & 1,721 \\
\hline
\end{tabular}

Teste de Homocedasticidade: Válido

ANOVA: Significativo

a. Preditores: (Constante), AT, AP, CO, AM

b. Variável Dependente: MOTIVACAO

Fonte: Dados da pesquisa no SPSS.

Para verificar a existência de autocorrelação entre os resíduos, foi utilizado o Teste de DurbinWatson, cujo resultado (D/W modelo1=2,048 > 0,05; D/W modelo2=1,721 > 0,05) indicou não haver problemas de autocorrelação entre os resíduos.

Na Tabela 3 são apresentadas as variáveis significantes divididas por grupo de Docentes e grupo de Técnicos Administrativos, com intervalo de confiança de $95 \%$. 
Tabela 3 - Regressão múltipla dos dados

\begin{tabular}{|c|c|c|c|c|c|c|c|c|c|c|}
\hline \multirow{2}{*}{ Tipo servidor } & \multirow{2}{*}{ Modelo } & \multicolumn{2}{|c|}{$\begin{array}{l}\text { Coeficientes não } \\
\text { padronizados }\end{array}$} & \multirow{2}{*}{$\begin{array}{c}\begin{array}{c}\text { Coeficientes } \\
\text { padronizados }\end{array} \\
\text { Beta }\end{array}$} & \multirow{2}{*}{$\mathbf{t}$} & \multirow{2}{*}{ Sig. } & \multicolumn{2}{|c|}{$\begin{array}{l}\text { 95,0\% Intervalo de } \\
\text { Confiança para B }\end{array}$} & \multicolumn{2}{|c|}{$\begin{array}{l}\text { Estatísticas de } \\
\text { colinearidade }\end{array}$} \\
\hline & & B & $\begin{array}{c}\text { Erro } \\
\text { Padrão }\end{array}$ & & & & $\begin{array}{c}\text { Limite } \\
\text { inferior }\end{array}$ & $\begin{array}{l}\text { Limite } \\
\text { superior }\end{array}$ & Tolerância & VIF \\
\hline \multirow{5}{*}{ Docente } & (Constante) & 2,059 & 0,248 & & 8,293 & 0 & 1,57 & 2,549 & & \\
\hline & $\mathrm{AT}$ & 0,553 & 0,139 & 0,379 & 3,982 & 0 & 0,279 & 0,827 & 0,436 & 2,293 \\
\hline & $1 \mathrm{AM}$ & $-0,06$ & 0,108 & $-0,049$ & $-0,561$ & 0,576 & $-0,273$ & 0,152 & 0,515 & 1,943 \\
\hline & $\mathrm{CO}$ & $-0,097$ & 0,128 & $-0,064$ & $-0,753$ & 0,452 & $-0,35$ & 0,156 & 0,556 & 1,799 \\
\hline & $\mathrm{AP}$ & $-0,243$ & 0,072 & $-0,253$ & $-3,376$ & 0,001 & $-0,386$ & $-0,101$ & 0,703 & 1,423 \\
\hline \multirow{5}{*}{ Técnico Administrativo } & (Constante) & 1,133 & 0,403 & & 2,815 & 0,005 & 0,341 & 1,925 & & \\
\hline & AT & $-0,148$ & 0,162 & $-0,061$ & $-0,911$ & 0,363 & $-0,467$ & 0,171 & 0,555 & 1,803 \\
\hline & $1 \mathrm{AM}$ & $-0,546$ & 0,128 & $-0,267$ & $-4,258$ & 0 & $-0,798$ & $-0,294$ & 0,638 & 1,567 \\
\hline & $\mathrm{CO}$ & 0,815 & 0,117 & 0,396 & 6,977 & 0 & 0,585 & 1,045 & 0,781 & 1,28 \\
\hline & $\mathrm{AP}$ & 0,306 & 0,084 & 0,228 & 3,647 & 0 & 0,141 & 0,471 & 0,645 & 1,551 \\
\hline
\end{tabular}

\section{a. Variável Dependente: MOTIVACAO}

Fonte: Dados da pesquisa com Docentes e Técnicos Administrativos - SPSS.

Nota:

Regressão múltipla por Valores de Ordem Superior extraídos do PVQ de Schwartz.

AT: Autotranscendência;

AM: Abertura à Mudança;

CO: Conservação;

AP: Autopromoção. 
No intuito de facilitar a análise da tabela de regressão múltipla, serão agrupados os 4 (quatros) valores de ordem superior para cada grupo (Docente e Técnico Administrativo).

Somente 2 (duas) variáveis são consideradas significantes para explicar o modelo do Docente: AT (com coeficiente $\beta=0,38$ e $\mathrm{p}<1 \%$ ) e AP (com coeficiente $\beta=-0,25$ e $\mathrm{p}<1 \%)$. Já as variáveis AM e $\mathrm{CO}$ não foram consideradas significantes para explicar o modelo proposto.

Podemos analisar a relação das variáveis citadas acima da seguinte forma: quanto maior for AT, maior será também a motivação do Docente. Em relação à AP, acontece o inverso, ou seja, quanto maior for AP menor será a motivação.

Referente ao modelo Técnico Administrativo pode-se perceber que 3 (três) variáveis são consideradas significantes e explicativas: $\mathrm{AM}$ (com coeficiente $\beta=-0,26 \mathrm{e} \mathrm{p}<1 \%$ ); $\mathrm{CO}$ (com coeficiente $\beta=0,39$ e $\mathrm{p}<1 \%$ e AP (com coeficiente $\beta=0,22$ e $\mathrm{p}<1 \%$ ). Somente a variável AT foi considerada como não significante para explicar o modelo.

A análise da relação das variáveis deste segundo modelo pode considerar a seguinte forma: quanto maior for $\mathrm{AM}$, menor será a motivação. Já em CO, quanto maior for esse valor, maior será a motivação do Técnico Administrativo. De forma similar, acontece com AP porque quanto maior ela for, maior será a motivação. Outro fator a ser destacado é que cada variável apresentou valor de VIF < 10, ou seja, as variáveis independentes não estão correlacionadas entre si, o que proporciona estimativas mais confiáveis.

No intuito de deixar mais evidente, são demonstradas de forma consolidada as hipóteses relacionadas na pesquisa bem como sua situação e coeficiente significante, no Quadro 2: 
Quadro 2 - Oito hipóteses em quatro perspectivas

\begin{tabular}{|c|c|c|c|}
\hline $\begin{array}{c}\text { Perspectivas } \\
\text { de valores de ordem } \\
\text { superior de } \\
\text { Schwartz } \\
\end{array}$ & Hipóteses e Grupo de trabalho & Situação & Coeficiente \\
\hline \multirow{2}{*}{ Conservação } & $\begin{array}{l}\text { H1) Há uma relação positiva entre o valor } \\
\text { pessoal de Conservação e a motivação do grupo } \\
\text { de trabalho de Docentes. }\end{array}$ & Rejeita-se. & - \\
\hline & $\begin{array}{l}\text { H2) Há uma relação positiva entre o valor } \\
\text { pessoal de Conservação e a motivação do grupo } \\
\text { de trabalho de Técnicos Administrativos. }\end{array}$ & Não se rejeita. & $0,39 * * *$ \\
\hline \multirow{2}{*}{$\begin{array}{l}\text { Abertura à } \\
\text { Mudança }\end{array}$} & $\begin{array}{l}\text { H3) Há uma relação negativa entre o valor } \\
\text { pessoal de Abertura à Mudança e a motivação do } \\
\text { grupo de trabalho de Docentes. }\end{array}$ & Rejeita-se. & - \\
\hline & $\begin{array}{l}\text { H4) Há uma relação negativa entre o valor } \\
\text { pessoal de Abertura à Mudança e a motivação do } \\
\text { grupo de trabalho de Técnicos Administrativos. }\end{array}$ & Não se rejeita. & $-0,26 * * *$ \\
\hline \multirow{2}{*}{ Autotranscendência } & $\begin{array}{l}\text { H5) Há uma relação positiva entre o valor } \\
\text { pessoal de Autotranscendência e a motivação do } \\
\text { grupo de trabalho de Docentes. }\end{array}$ & Não se rejeita. & $0,37^{* * *}$ \\
\hline & $\begin{array}{l}\text { H6) Há uma relação positiva entre o valor } \\
\text { pessoal de Autotranscendência e a motivação do } \\
\text { grupo de trabalho de Técnicos Administrativos. }\end{array}$ & Rejeita-se. & - \\
\hline \multirow{2}{*}{ Autopromoção } & $\begin{array}{l}\text { H7) Há uma relação negativa entre o valor } \\
\text { pessoal de Autopromoção e a motivação do } \\
\text { grupo de trabalho de Docentes. }\end{array}$ & Não se rejeita. & $-0,25 * *$ \\
\hline & $\begin{array}{l}\text { H8) Há uma relação negativa entre o valor } \\
\text { pessoal de Autopromoção e a motivação do } \\
\text { grupo de trabalho de Técnicos Administrativos. }\end{array}$ & Rejeita-se. & $0,23 * * *$ \\
\hline
\end{tabular}

Fonte: Dados da pesquisa.

Nota:

$* * \mathrm{p}<0,01 ; * * * \mathrm{p}<0,001$.

\section{Discussão dos resultados}

Para facilitar o entendimento das hipóteses em relação a cada grupo, primeiro será analisado o grupo de trabalho Docentes e posteriormente o grupo de trabalho Técnicos Administrativos.

\section{a) Análise dos Docentes:}

Os valores de Conservação e Abertura à Mudança não apresentaram relações significativas com os construtos de Motivação no grupo de trabalho Docente, não oferecendo suporte para H1 e H3. Isso esclarece que tanto a Conservação, quanto a Abertura à Mudança são pouco expressivas para explicar a Motivação no grupo de trabalho Docentes pertencentes aos IFES.

Já as hipóteses H5 e H7 não foram rejeitadas, ou seja, o valor de Autotranscendência mostrouse positiva e significativamente associado ao construto de Motivação no grupo de trabalho Docente. Confirmando o sugerido na hipótese H7, o valor de Autopromoção se relacionou negativamente com a variável dependente Motivação no grupo de trabalho Docente.

Esse resultado endossa a relação de oposição conceitual entre Autopromoção e Autotranscendência e a associação negativa entre os polos dos valores pessoais propostas na teoria de valores de Schwartz (1994), conforme apresentado na Figura 1.

b) Análise dos Técnicos Administrativos: 
As hipóteses H2 e H4 não foram rejeitadas, ou seja, o valor de Conservação demonstrado na H2 mostrou-se positiva e significativamente associado ao construto de Motivação no grupo de trabalho Técnico Administrativo. Validando o sugerido na hipótese H4, o valor de Abertura à Mudança relacionou-se negativamente com a variável dependente Motivação no grupo de trabalho Técnico Administrativo. Esse resultado comprova a relação de oposição conceitual entre Conservação e Abertura à Mudança e a associação negativa entre os polos dos valores pessoais propostas na teoria de valores de Schwartz (1994), como exposto na Figura 1.

De forma contrária, o valor Autotranscendência não apresentou relação significante com o construto de Motivação no grupo de trabalho Técnico Administrativo; assim, não sustenta a hipótese H6, e isso significa que a Autotranscendência é pouco relevante para explicar a Motivação no grupo de trabalho Técnico Administrativo pertencente aos IFES.

Diferentemente do sugerido na hipótese H8, o valor de Autopromoção também se relacionou positivamente com a variável Motivação no grupo de trabalho Técnico Administrativo, e o proposto nesta hipótese seria de relação negativa, por conseguinte, tal hipótese deve ser rejeitada.

Esse resultado converge com o estudo de Gorski, Tomazzoni, dos Santos, Tonin e Costa (2015), no qual destacam que muitos técnicos-administrativos em educação têm buscado qualificação constante. Foi verificado que servidores têm procurado mais qualificação em sua área, e a comprovação desse fato é que vários profissionais têm apresentado diploma de graduação, mestrado e doutorado no tempo em que foi realizada esta pesquisa. É importante destacar que em muitas situações as pessoas já tinham concluído o curso superior ou de pós-graduação muito antes de fazerem parte do quadro de pessoal ou colaboradores da Instituição. Isso leva a crer que esse grupo enfatiza o tipo motivacional Realização, que busca o sucesso pessoal e o reconhecimento social por meio da demonstração das competências (Schwartz, 1994).

Figura 2 - Adaptado a partir da estrutura circular dos valores ilustrando conflito e congruência entre os valores motivacionais

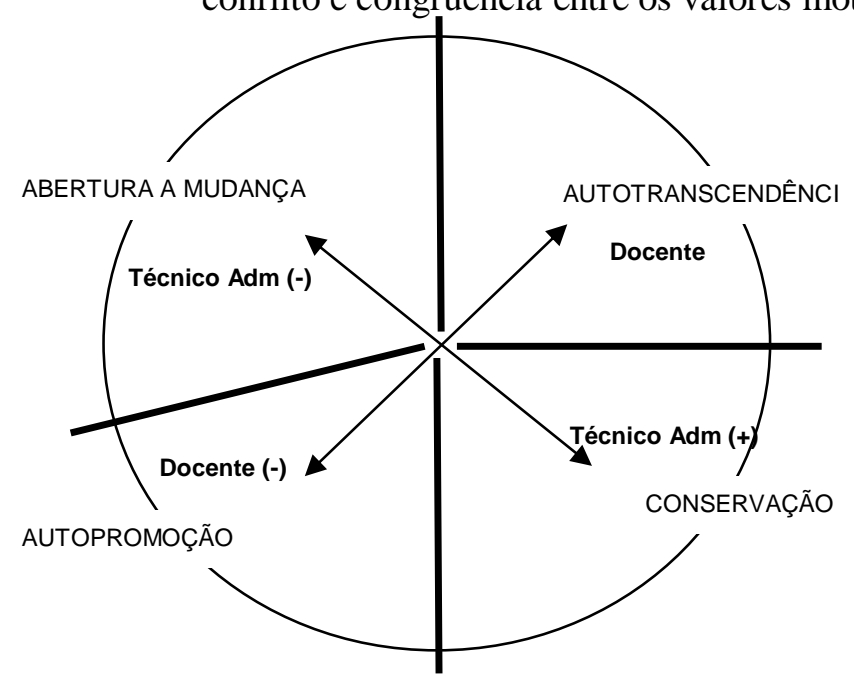

Fonte: Schwartz (2005) e dados da pesquisa. 
A Figura 2 trata-se da demonstração dos resultados encontrados para cada grupo (Docente e Técnico Administrativo), levando em consideração a relação de oposição entre as polaridades dos valores de ordem superior, bem como a disposição positiva e negativa que o grupo desenvolve com os valores (Schwartz, 2005).

Podemos perceber que os resultados da pesquisa confirmam o exposto na teoria referente à dicotomia dos valores (Schwartz, 2005; Tamayo \& Porto, 2009). Para os Técnicos, o valor Conservação apresentou-se mais importante, se comparado com Abertura à Mudança. Observando os Docentes, o valor Autotranscendência teve mais relevância do que o valor Autopromoção. Evidencia-se, dessa forma, o perfil em destaque que os gestores devem observar para reter o capital humano qualificado.

\section{1) Dilema dos Docentes:}

Podemos dizer, após observar os resultados, que o dilema de ser motivado e em permanecer na organização da maioria dos Docentes investigados é prioritária Autotranscendência e deixa a entender que o mais importante é: passar os seus conhecimentos para as gerações futuras, optar pelo cuidado com a preservação do planeta, fortalecer as relações sadias uns com os outros, e de alguma forma transmitir em suas ações acadêmicas que dão pouca importância para o status social e o prestígio individual.

\section{2) Dilema dos Técnicos Administrativos:}

Já o dilema da maioria dos Técnicos Administrativos pesquisados é preferir a conservação, visto que estes são técnicos conservadores que tendem a querer permanecer em uma instituição pública de educação se ela oferecer um ambiente de trabalho que não apresente mudanças constantes em suas políticas, pois eles querem desenvolver projetos e atividades mais duradouras. Apreciam a segurança nas relações e a continuidade dos processos.

Para os Técnicos inovadores, isso pode apresentar menor facilidade em se adaptar, pois a opção da maioria é por um ambiente de trabalho com poucas mudanças e sem muitos desafios constantes.

\section{Conclusão}

O objetivo deste estudo foi identificar os Valores Motivacionais que se destacam no grupo de trabalho Docentes e no grupo de trabalho Técnicos Administrativos presentes em uma Instituição Pública de Ensino, que podem ser distinguidos como diferentes.

Um primeiro achado desta pesquisa foi que os resultados sugerem que realmente existem diferenças na percepção dos valores motivacionais presentes em cada grupo de trabalho pesquisado, confirmado não se tratar de grupos homogêneos, o que representa um avanço na literatura a respeito das influências das metas motivacionais em distintos grupos de trabalho de servidores públicos da educação.

Isso confirma a teoria de Schwartz (2005) de que os grupos se diferenciam significativamente na importância relativa que atribuem a seus valores. Ou seja, os indivíduos e os grupos possuem prioridade ou hierarquias axiológicas diferentes. 
Prioridades axiológicas são hierarquizações dos valores mais influentes na vida de uma pessoa, e tais valores são considerados de suma importância para um indivíduo ou um determinado grupo e concebem, desta forma, uma classificação ordenada dos valores que serão assumidos como primários e os que serão considerados como secundários (Calvosa, Serra, \& Almeida, 2011).

O valor Autotranscendência foi significante para o grupo de trabalho Docentes. A Autotranscendência relacionou-se positivamente com a motivação desse grupo, portanto quanto maior a percepção desse valor, maior será a resposta favorável no que diz respeito à motivação deles.

Por conseguinte, podemos considerar que os Docentes dão mais importância em transmitir conhecimentos para as gerações futuras, priorizam o cuidado com a preservação do planeta e das relações sadias, ao invés da busca por sucesso pessoal, pelo prestígio, pela preservação do status social e pelo controle e domínio sobre as pessoas e os recursos, que ficam em segundo plano.

Referente ao grupo de trabalho Técnicos Administrativos, o valor estatisticamente significante foi Conservação, que se relacionou positivamente com a motivação deles. Logo, quanto maior a percepção desse valor, maior será a resposta favorável no que se refere à motivação dos Técnicos, e isso leva a crer que eles priorizam uma instituição com uma política mais duradoura a mudanças e desafios constantes.

Em oposição, o valor Abertura à Mudança teve relação negativa; então quanto maior for a assimilação desse valor, menor será a resposta aceitável referente à motivação neste grupo. Tal resultado sugere preferência pelo valor Conservação; assim as metas motivacionais do valor Abertura à Mudança ficariam em segundo plano, metas essas que seriam independência de pensamento e ação, excitação, novidade e desafio na vida, bem como prazer e a procura em satisfazer seus desejos.

Evidencia-se, desta forma, o dilema dos indivíduos de cada grupo em permanecer ou não no local de trabalho, desde que suas expectativas de valores motivacionais sejam supridas, o que confirma a teoria acerca da dicotomia/dualidade de valores apresentada pelos grupos.

Em termos práticos, com os resultados obtidos na pesquisa, os gestores podem traçar melhores estratégias de gestão de carreiras que atendam ao perfil de cada grupo e colaborem com a permanência do profissional qualificado na instituição, seja criando capacitações específicas para cada grupo, elaboração de ferramentas que consigam capturar as sugestões dos próprios servidores, e ponha as mais requisitadas e possíveis em ação, e anualmente criar indicadores para medir a motivação desses grupos.

A pesquisa apresenta algumas limitações: os dados com corte transversal, e não longitudinal, não permitem realizar inferências causais, mas apenas relacionais. Outra limitação importante refere-se ao fato de a amostra ser composta apenas por pessoas de um Instituto Federal de Educação. Devido à diferença de cultura e costumes presentes em um país com dimensões continentais, talvez se esta pesquisa fosse aplicada em Institutos de outros estados brasileiros tivéssemos uma confirmação mais precisa do objetivo da pesquisa.

Para os gestores, a pesquisa permite sugerir que as estratégias que abordam os servidores desses dois grupos como iguais, e com as mesmas perspectivas de crescimento nessa instituição, não permitem 
explorar com qualidade o potencial de cada grupo. Esses fatos levam a crer que podem sim colaborar com a desmotivação e perda de capital humano qualificado nas organizações.

Como sugestão, faz-se necessário o desenvolvimento de políticas de gestão de pessoas e capacitações mais específicas para esses dois grupos com perfil motivacional diferenciado, que visem à manutenção da motivação de seus profissionais, a fim de possibilitar a elaboração de mecanismos que possam dinamizar o desempenho, pautando-se nos valores motivacionais apresentados por cada grupo.

Pesquisas futuras poderão realizar estudos com dados longitudinais para possibilitar inferências causais. Também é proposta a realização desta pesquisa em outros Institutos Federais em distintos estados para possibilitar a confirmação mais precisa e ter maior generalização dentro do território brasileiro desses valores motivacionais que receberam destaque em cada grupo.

\section{Referências}

Abessolo, M., Rossier, J., \& Hirschi, A. (2017). Basic values, career orientations, and career anchors: Empirical investigation of relationships. Frontiers in psychology, 8, 1556.

Bilsky, W., Janik, M., \& Schwartz, S. H. (2011). The structural organization of human values Evidence from three rounds of the European Social Survey (ESS). Journal of Cross-Cultural Psychology, 42(5): 759-776. DOI: 10.1177/0022022110362757 jccp.sagepub.com.

Brown, A. et al. (2003). Strategic talent retention: using measurement to keep the best. Strategic HR Review, 2(4): 22-27.

Calvosa, M. V. D., Serra, F. A. R., \& Almeida, M. I. R. (2011). Quais são as prioridades axiológicas dos líderes empresariais? Análise dos seus valores pessoais a partir do inventário de valores SVS de Schwartz. Anais do Encontro de Gestão de Pessoas e Relações de Trabalho - EnGPR, João Pessoa, $\mathrm{PB}$, Brasil, 3.

Carrara, Tânia M. P., Nunes, Simone C., \& Sarsur, Amyra M. (2014). Fatores de retenção, permanência e desligamento de talentos e de performers. RACE, Revista de Administração, Contabilidade e Economia, Joaçaba: Ed. Unoesc, 13(3): 1119-1148.

Davidov, E., Schmidt, P., \& Schwartz, S. H (2008). Bringing values back in: the adequacy of the European Social Survey to measure values in 20 countries. Public Opinion Quarterly, 72(3): 420445. DOI: https://doi.org/10.1093/poq/nfn035.

Dutra, J. S (2011) . Gestão de pessoas: modelo, processos, tendências e perspectivas. São Paulo: Atlas.

Ferreira, A., Fuerth, L. R., \& Esteves, R. C. P. M (2006). Fatores de motivação no trabalho: o que pensam os líderes. Anais do Encontro da ANPAD - EnANPAD, Salvador, BA, Brasil, 30.

Gorski, A. D., Tomazzoni, G. C., dos Santos, A. S., Tonin, S., \& Costa, V. M. F. (2015). Participação dos técnico-administrativos em educação nas ações de educação formal e do impacto do treinamento no trabalho. Revista Pensamento e Realidade, PUCSP, 30(1).

Gouveia, V. V. (2003). A natureza motivacional dos valores humanos: evidências acerca de uma nova tipologia. Estudos de Psicologia, 8(3): 431-443. DOI: http://dx.doi.org/10.1590/S1413-

294X2003000300010. 
Hair Jr., J. F., Black, W.C., Babin, B.J., Anderson, R.E., \& Tatham, R.L. (2005). Análise multivariada de dados. 5.ed. Porto Alegre: Bookman, 2005.

Hair Jr., J. F., Babin, B.J., Money, A.H., \& Phillip, S. (2009). Fundamentos e métodos de pesquisa em administração. Porto Alegre: Bookman.

Holtom, B. et al. (2008). Turnover and retention research: a glance at the past, a closer review of the present, and a venture into the future. The Academy of Management Annals, New York, 2(1): 231274.

Houston, D. J. (2000, out.). Public-service motivation: a multivariate test. Journal of Public Administration Research \& Theory (Transaction), 10(4): 713-727.

Lombardi, M. F. S., Araujo, B. F. V. B. De, \& Teixeira, M. L. M. (2010, nov./dez.). Implicações dos valores básicos de estudantes no ensino de administração: um estudo em dois cursos de graduação em administração na cidade de São Paulo. Administração: Ensino e Pesquisa. RAEP, Rio de Janeiro, 11(4): 527-550. DOI: 10.13058/raep.2010.v11n4.128.

Marras, J. P. (2011). Administração de recursos humanos: do operacional ao estratégico. 14. ed. São Paulo: Saraiva.

Mitchell, T. R. et al. (2001). Why people stay: using job embeddedness to predict voluntary turnover. Academy of Management Journal, (44): 1102-1122.

Oliveira, R. R., Limongi-França, A. C., Nomelini, Q. S. S., Castro, D. S. P., Alves, L. R., \& Zatta, F. N. (2015). A qualidade de vida no trabalho dos professores da Rede Federal de Educação Profissional e Tecnológica: percepções com a metodologia BPSO alinhado à qualidade da educação. Anais do Encontro de Gestão de Pessoas e Relações de Trabalho - EnGPR, Salvador, BA, Brasil, 5.

Pacheco, E. (org). (2011). Institutos Federais: uma revolução na educação profissional e tecnológica. São Paulo: Moderna, 2011.

Pogorzelski, S., Harriott, J., \& Hardy, D (2011). Finding keepers: novas estratégias para contratar e reter talentos. Porto Alegre: Bookman.

Relatório de Gestão. (2015). Instituto Federal de Educação, Ciência e Tecnologia do Espírito Santo. Vitória: Instituto Federal de Educação, Ciência e Tecnologia do Espírito Santo. Recuperado em 28 janeiro, 2016, de http://prodi.ifes.edu.br//prodi/relatorio_gestao/Relatorio_de_Gestao_2015.pdf.

Robbins, S.P., Judge, T. A., \& Sobral, F. (2011). Comportamento organizacional: teoria e prática no contexto brasileiro. 14. ed. São Paulo: Pearson Prentice Hall.

Ros, M. (2006). Psicologia social dos valores: uma perspectiva histórica. In: Ros, M., \& Gouveia, V. V. (Org.). Psicologia social dos valores humanos. São Paulo: Senac, 23-53.

Sagiv, L., \& Schwartz, S. H. (2000). Value priorities and subjective well-being: Direct relations and congruity effects. European Journal of Social Psychology, 30: 177-198. DOI: 10.1002/(SICI)10990992(200003/04)30:2<177::AID-EJSP982>3.0.CO;2-Z.

Sambiase-Lombardi, M. F. S., Teixeira, M. L. M., Bilsky, W., Araujo, B. F. V. B., \& Domenico, S. M. R. (2010). Confrontando Estruturas de Valores: Um Estudo Comparativo entre PVQ-40 e PVQ-21. Anais do Encontro de Estudos Organizacionais da ANPAD (EnEO), Florianópolis, SC, Brasil, 6.

Saraiva, L. A. S. (2002, jan./abr.). Cultura organizacional em ambiente burocrático. $R A C$, 6(1): 187- 
207. DOI: http://dx.doi.org/10.1590/S1415-65552002000100011.

Schwartz, S. H. (1992). Universals in the content and structure of values: theoretical advances and empirical tests in 20 countries. In: ZANNA, M. (Ed.). Advances in experimental social psychology, New York: Academic Press, 25: 1-65.

Schwartz, S. H. (1994). Are there universal aspects in the structure and contents of human values? Journal of Social Issues, 50(4): 19-45. DOI: 10.1111/j.1540-4560.1994.tb01196.x.

Schwartz, S. H., \& Ros, M. (1995). Values in the West: a theoretical and empirical challenge to the Individualism-Collectivism cultural dimension. World Psychology, 1: 99-122.

Schwartz, S. H, \& Bardi, A. (1997). Influences of adaptation to communist rule on value priorities in Eastern Europe. Political Psychology, 18(2): 385-410. DOI: 10.1111/0162-895X.00062.

Schwartz, S. H., Verkasalo, M., Antonovsky, A., \& Sagiv, L. (1997). Value priorities and social desirability: Much substance, some style. British Journal of Social Psychology, 36: 3-18, 1997. DOI: $10.1111 / \mathrm{j} .2044-8309.1997 . t b 01115 . x$

Schwartz, S. H. (1999). A theory of cultural values and some implications for work. Applied psychology: international review, 48(1): 23-47. DOI: 10.1111/j.1464-0597.1999.tb00047.x.

Schwartz, S. H. (2001). Value hierarchies across cultures: taking a similarities perspective. Journal of Cross-Cultural Psychology, 32: 268-290.

Schwartz, S. H., Melech, G., Lehmann, A., Burgess, S., Harris, M., \& Owens, V. (2001). Extending the cross-cultural validity of the theory of basic human values with a different method of measurement. Journal of Cross-Cultural Psychology, 32(5): 519-542.

Schwartz, S. H., \& Boehnke, K. (2004). Evaluating the structure of human values with confirmatory factor analysis. Journal of Research in Personality, 38: 230-255. DOI: https://doi.org/10.1016/S0092-6566(03)00069-2.

Schwartz, S. H. (2005). Valores humanos básicos: seu contexto e estrutura intercultural. In: Tamayo, A.; Porto, J. B. (Orgs). Valores e comportamentos nas organizações, Petrópolis, RJ: Vozes, 21-55.

Schwartz, S. H. (2006). Value orientations: Measurement, antecedents and consequences across nations. In Jowell, R., Roberts, C., Fitzgerald, R., \& Eva, G. (Eds.) Measuring attitudes crossnationally - lessons from the European Social Survey, 169-203.

Schwartz, S. H. (2012). An overview of the Schwartz theory of basic values. Online Readings in Psychology and Culture, 2(1): 1-20. DOI: http://dx.doi.org/10.9707/2307-0919.1116.

Schwartz, S. H., Cieciuch, J., Vecchione, M., Davidov, E., Fischer, R., Beierlein, C., ... \& DirilenGumus, O. (2012). Refining the theory of basic individual values. Journal of Personality and Social Psychology, 103(4): 663-688. DOI: http://dx.doi.org/10.1037/a0029393.

Smith, P. B., \& Schwartz, S. H. (Eds.). (1997). Handbook of cross-cultural psychology, 77-118.

Tamayo, A. (1994). Hierarquia de valores transculturais e brasileiros. Psicologia: teoria e pesquisa, Brasília, 10(2): 269-286.

Tamayo, A., \& Paschoal, T. (2003, out./dez.). A relação da motivação para o trabalho com as metas do trabalhador. $R A C, 7(4): 33-54$. DOI: http://dx.doi.org/10.1590/S1415-65552003000400003. 
Tamayo, A., \& Porto, J. B. (Orgs). (2005). Valores e comportamentos nas organizações. Petrópolis, RJ: Vozes.

Tamayo, A., \& Paschoal, T. (2007). Contribuições ao estudo dos valores pessoais, laborais e organizacionais. Psicologia: teoria e pesquisa, Brasília, 23(especial): 17-24.

Tamayo, A., \& Porto, J. B. (2009, jul-set.). Validação do questionário de perfis de valores (QPV) no Brasil. Psicologia: teoria e pesquisa, Brasília, 25(3): 369-376.

Tavares, M. G. (2012). Evolução da Rede Federal de Educação Profissional e Tecnológica: as etapas históricas da educação profissional no Brasil. Anais do Seminário de Pesquisa em Educação da Região Sul - ANPED, Rio Grande do Sul, RS, Brasil, 6.

Anexo

Bloco I

Neste bloco, nossa intenção é traçar o perfil dos participantes da pesquisa.

Caro servidor (a) do Ifes, encontra-se abaixo um breve questionário que poderá responder em $\mathbf{5}$ minutos.

A pesquisa será realizada através do questionário a seguir e tem como objetivo principal avaliar a relação entre os valores motivacionais dos Docentes e os valores motivacionais dos Técnicos Administrativos.

Sua participação será de suma importância para tentarmos entender quais os valores motivacionais presentes nestes 2 (dois) grupos de trabalho de servidores públicos da educação.

É importante destacar que não há resposta certa ou errada, pois a resposta para cada questão deve ser baseada em suas opiniões pessoais. Assumo a responsabilidade de manter sigilo sobre suas respostas pessoais. Além disso, os dados desta pesquisa serão analisados de maneira agrupada, assim você não precisará se identificar no questionário.

Dados Demográficos

1) Você é Docente ou Técnico Administrativo?

2) Nome do Campus?

3) Quantos anos tem o seu Campus? 
4) Quantos anos você está no atual Campus?

5) Há quanto anos você trabalho no Ifes?

6) Idade?

7) Gênero?

( ) Masculino ( ) Feminino

8) Estado Civil?

( ) solteiro(a)

( ) casado(a)

( ) separado(a)

( ) viúvo(a)

( ) outros

9) Quantos filhos?

( ) nenhum

( ) 1

( ) 2

( ) 3

( ) mais de 3

10) Qual o seu nível de escolaridade?

( ) sem escolaridade

( ) ensino fundamental ( $\left.1^{\circ} \mathrm{grau}\right)$ incompleto

( ) ensino fundamental ( $\left.1^{\circ} \mathrm{grau}\right)$ completo

( ) ensino médio ( $2^{\circ}$ grau) incompleto

( ) ensino médio ( $2^{\circ}$ grau) completo

( ) superior incompleto

( ) superior completo

( ) especialização

( ) mestrado

( ) doutorado

( ) outros

11) Função Profissional? 

( ) Direção
( ) Coordenação
( ) Gerente
( ) Reitor
( ) Pró -Reitor(a)
( ) outros

12) Setor de Atuação?

( ) Pedagógico

( ) Administrativo

( ) outros

\section{Bloco II}

13) Em uma escala de 1 a 5 marque abaixo o seu Nível de Motivação em trabalhar na atual Instituição Pública de Educação (IFES).
( ) Nada motivado
( ) Pouco motivado
( ) Mais o menos motivado
( ) Motivado
( ) Muito Motivado

As questões abaixo tratam da pergunta acerca da motivação dos respondentes (escala Likert de 1 a 5) e do PVQ-40 de Schwartz, que aborda da importância dos valores individuais. Conforme a nossa compreensão, valores são princípios que guiam a vida das pessoas. Nós estamos particularmente interessados em saber quais valores são mais ou menos importantes para você como princípios centrais na sua vida.

Abaixo você encontrará descrições de alguns tipos de pessoas. Leia cada descrição e avalie o quanto cada uma dessas pessoas é parecida com você. Selecione a opção que indica o quanto a pessoa descrita se parece com você. Não há resposta certa ou errada. Responda de acordo com o seu entendimento e interpretação. Não deixe nenhum item em branco. 
Questionário de Perfil de Valores (PVQ-40) de Schwartz (TAMAYO e PORTO, 2009):

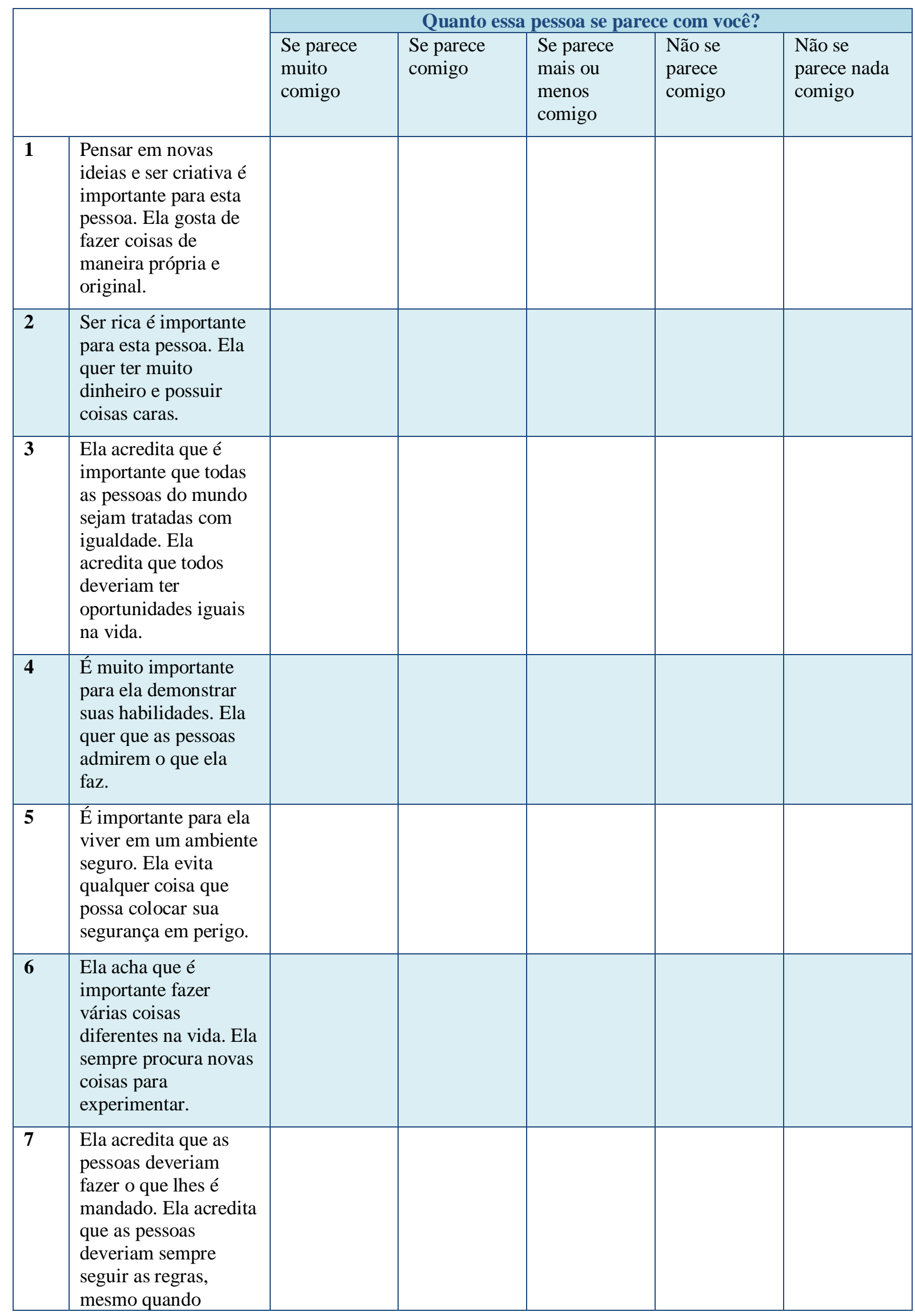


Moreira, P. R. B., Teixeira, A., \& Locatelli, O. (2020, July/Sept.). Valores motivacionais nas organizações: um estudo com diferentes grupos de trabalho de servidores públicos da educação

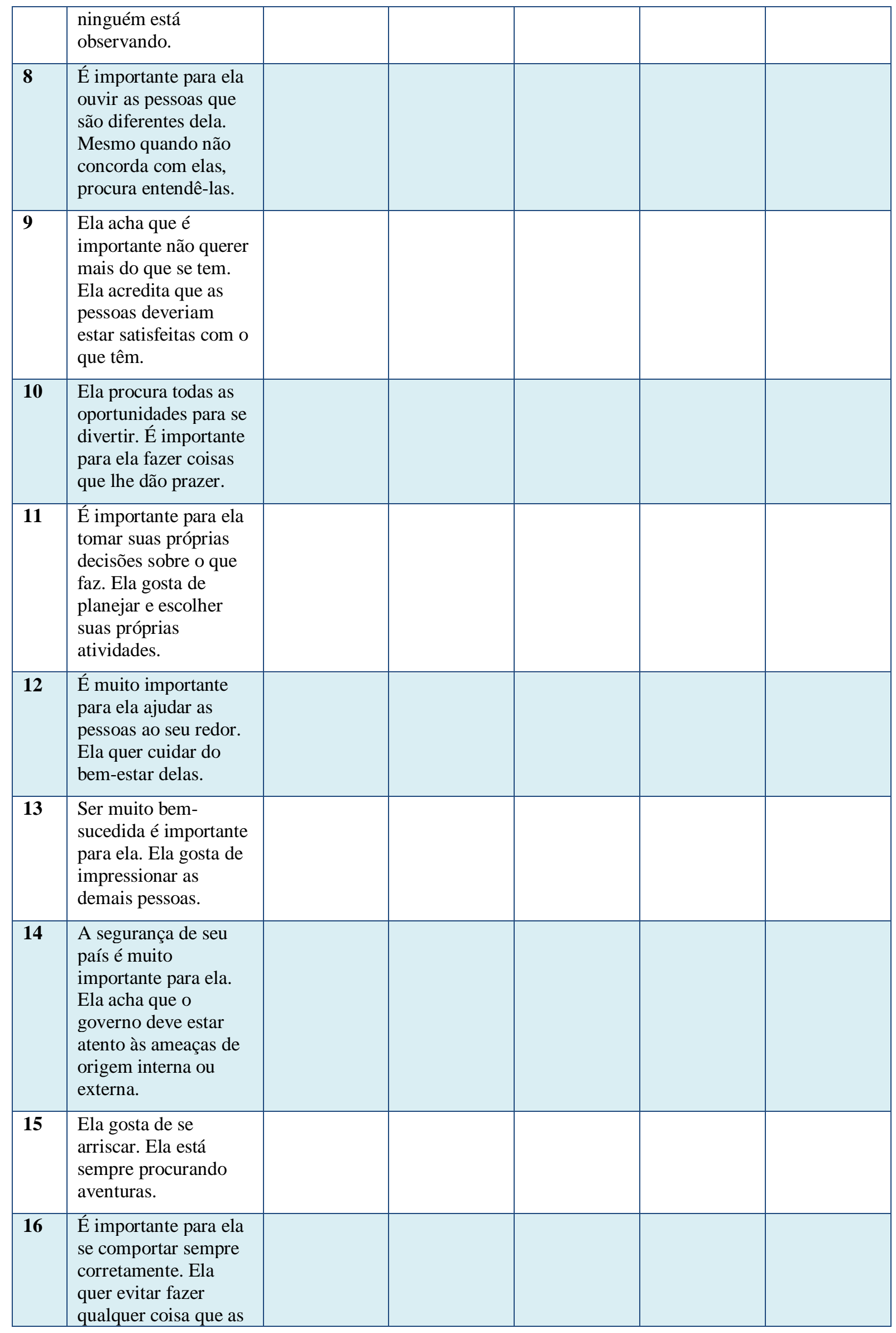




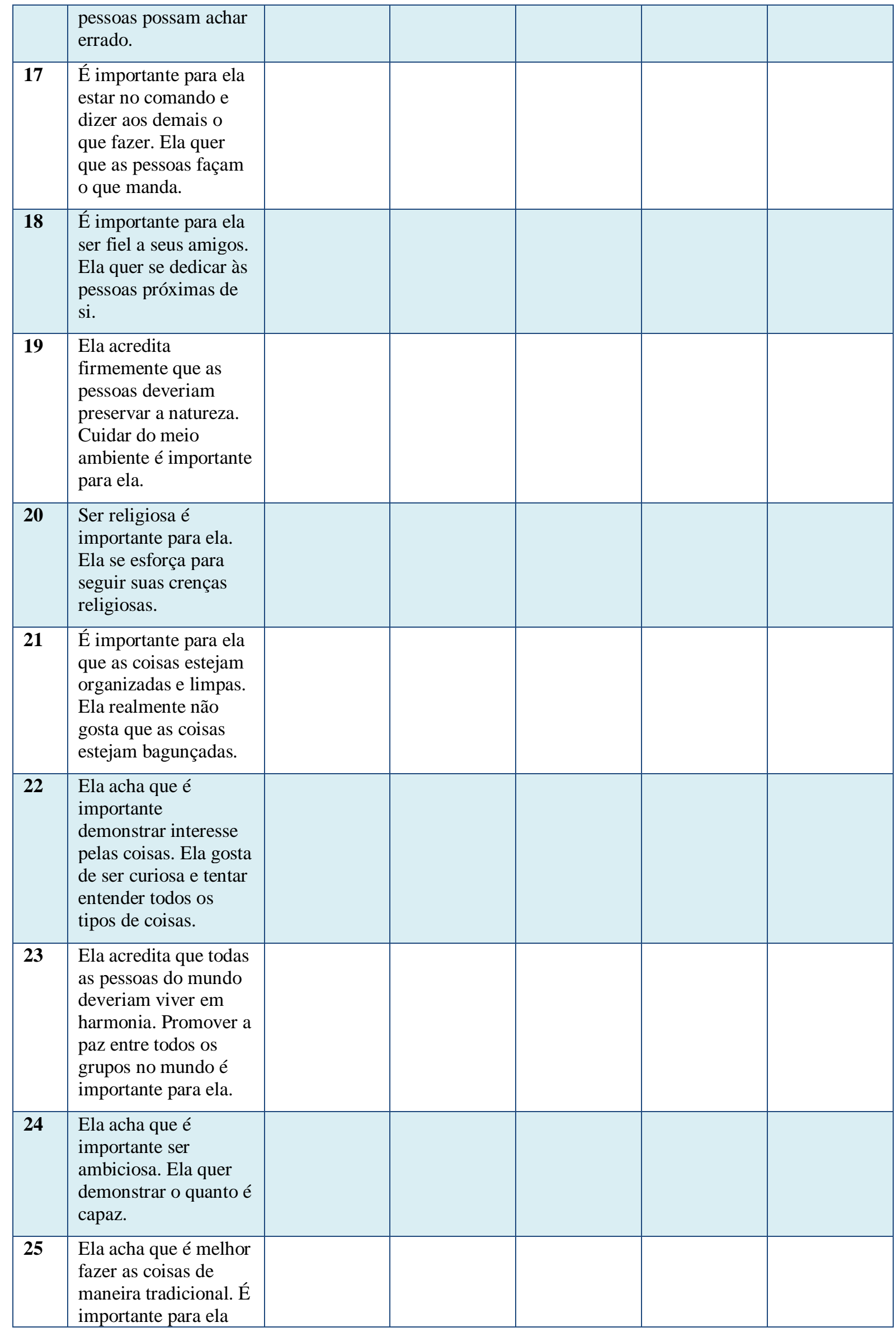


Moreira, P. R. B., Teixeira, A., \& Locatelli, O. (2020, July/Sept.). Valores motivacionais nas organizações: um estudo com diferentes grupos de trabalho de servidores públicos da educação

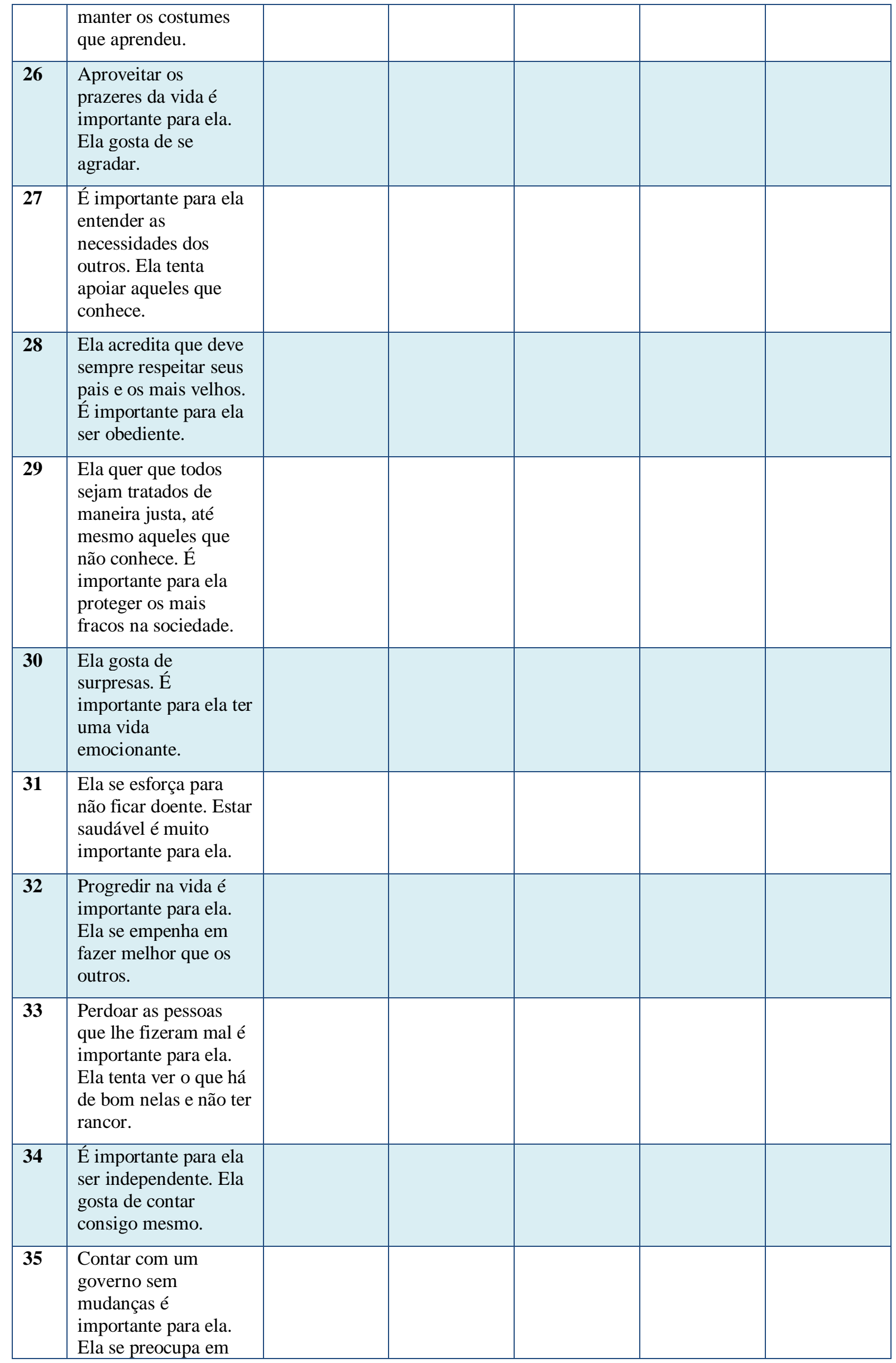




\begin{tabular}{|l|l|l|l|l|l|}
\hline & $\begin{array}{l}\text { manter a ordem social } \\
\text { do jeito que está. }\end{array}$ & & & & \\
\hline 36 & $\begin{array}{l}\text { É importante para ela } \\
\text { ser sempre educada } \\
\text { com os outros. Ela } \\
\text { tenta nunca } \\
\text { incomodar ou irritar } \\
\text { os outros. }\end{array}$ & & & & \\
\hline $\mathbf{3 7}$ & $\begin{array}{l}\text { Ela realmente quer } \\
\text { aproveitar a vida. } \\
\text { Divertir -se é muito } \\
\text { importante para ela. }\end{array}$ & & & & \\
\hline $\mathbf{3 8}$ & $\begin{array}{l}\text { É importante para ela } \\
\text { ser humilde e } \\
\text { modesta. Ela tenta } \\
\text { não chamar atenção } \\
\text { das pessoas para si. }\end{array}$ & & & & \\
\hline $\mathbf{3 9}$ & $\begin{array}{l}\text { Ela sempre quer ser } \\
\text { aquela a tomar } \\
\text { decisões. Ela gosta de } \\
\text { liderar. }\end{array}$ & & & & \\
\hline $\mathbf{4 0}$ & $\begin{array}{l}\text { É importante para ela } \\
\text { se adaptar e se ajustar } \\
\text { à natureza. Ela } \\
\text { acredita que as } \\
\text { pessoas não deveriam } \\
\text { modificar a natureza. }\end{array}$ & & & & \\
\hline
\end{tabular}

